\title{
La adición del amparo local en la Constitución de Guanajuato en México como respuesta a una justicia globalizada
}

The addition of legal protection in the constitution of Guanajuato in México as a response to a globalized justice system.

\author{
Antonio Olguín Torres ${ }^{1}$ \\ (iD) https://orcid.org/0000-0002-4843-2983 \\ Universidad de Guanajuato, México
}

\section{Como referenciar este artículo:}

Olguín Torres, A. (2020) La adición del amparo local en la Constitución de Guanajuato en México como respuesta a una justicia globalizada. Revista Ciencia Jurídica y Política, 88-104. Recuperado de: https://portalderevistas.upoli.edu.ni/index.php/5revciencasjuridicasypoliticas/article/view/645

\section{RESUMEN}

En un mundo globalizado por el derecho, la adición de nuevos mecanismos de justicia constitucional local como el amparo local en la fracción XV del artículo 88 de la Constitución Política del Estado de Guanajuato, propicia una mejor tutela judicial efectiva de los derechos humanos incluidos tanto en los tratados internacionales, en la Constitución Nacional de México y en las Constitución Particular del Estado de Guanajuato, pues se crea un nuevo instrumento jurisdiccional de justicia constitucional en el ámbito local al alcance de los gobernados que busca de garantizar de forma rápida y efectiva algún derecho cuando éste ha sido vulnerado por la autoridad.

Palabras Claves: justicia global, derecho constitucional, instrumentos procesales constitucionales, amparo local, Constitución del Estado de Guanajuato, México.

\begin{abstract}
In a globalized world of law, the addition of new mechanisms of local constitutional justice such as legal protection in section XV of article 88 of the Political Constitution of the state of Guanajuato, promotes better effective judicial protection of the human rights included in international treaties, in the National Constitution of Mexico and in the Particular Constitution of the state of Guanajuato, a new judicial instrument of constitutional justice is created at the local level for governed, which seeks to guarantee a right and effectively when it has been violated by the authority.
\end{abstract}

Key Word: Global justice, constitutional right, constitutional procedural instruments, legal protection, Constitution of the state of Guanajuato, Mexico. 


\section{Introducción}

La inclusión de un nuevo mecanismo de justicia constitucional en el Estado de Guanajuato, como lo es el amparo local, adicional al existente en la justicia constitucional nacional (amparo federal), queda inmerso en el fortalecimiento de un auténtico federalismo, propiciado por la interconectividad generada por la globalización del derecho que impacta en todas las esferas competenciales de las autoridades, incluyendo la local.

El enfoque metodológico de la presente investigación es principalmente documental. Bajo este método, se estudiarán las principales posturas académicas existentes en torno a la existencia de los mecanismos de justicia constitucional local en los Estados de la República Mexicana, y como, en el caso de Guanajuato existe un incipiente desarrollo de tales mecanismos.

Además, el planteamiento metodológico de la hipótesis se centra en uno de carácter predictivo, es decir, es el tipo de método que busca incidir en la conducta futura humana (predecirla) pues mediante la adición de un nuevo mecanismo de justicia constitucional en la fracción XV del artículo 88 de la Constitución Política del Estado de Guanajuato, con la correspondiente reforma y adición de la Ley Reglamentaria de la fracción XV del artículo 88 de la Constitución Local de Guanajuato, la población tendría acceso al amparo local como un mecanismos de justicia más cercano, pronto y efectivo.

Con ello se fortalecería al Estado de Guanajuato en el marco de un auténtico federalismo, sobre todo en estos tiempos en donde aparece ese fantasma del Supremo Poder Conservador del Siglo XIX (Poder Federal Actual) que busca ampliar sus competencias en detrimento de las locales, y que se plantea esta hipótesis en el marco de lo que hiciera en Yucatán Don Manuel Crescencio Rejón, con la creación del juicio de amparo, que posteriormente se llevaría al ámbito federal, pero olvidando que su origen se dio en el ámbito local.

La relación entre el constitucionalismo y la protección de los derechos humanos ha estado intrínsecamente relacionados en las democracias modernas globalizadas, y en el caso de México no es la excepción, pues dos reformas a la Constitución Políticas de los Estados Unidos Mexicanos (en adelante CPEUM) resultaron trascendentes para ver una nueva forma de abordar la definición y defensa jurisdiccional de los derechos humanos en México: las reformas de Amparo de 6 y 10 de junio de 2011 en materia de derechos humanos, y ello tiene un profundo impacto en el constitucionalismo local.

Ello se debe a que le concepto de "todas las autoridades", incluye a las locales, deben reconocer y garantizar todos los derechos humanos reconocidos en todos los tratados, ya sea que sean expresamente de derechos humanos o no; este planteamiento excede el problema planteado en esta investigación, por lo que sólo se dejará apuntado, lo que es importante recalcar es que una "apertura a una visión cualitativamente distinta de los DH (derechos humanos) una que en sus líneas de desenvolvimiento coloca a nuestro país en la era del diálogo transfronterizo de los derechos, define las obligaciones de las autoridades (todas, 
incluyendo las locales) en relación con ellos, al igual que dota de herramientas de interpretación que permite salvaguardar mejor sus contenidos" (Collí Ek, 2019, p. 3).

Además, existe ahora un diálogo entre los tribunales nacionales como lo es la Suprema Corte de Justicia de la Nación (en adelante, SCJN), y la Corte Interamericana de Derechos Humanos (en adelante CoIDH), porque las determinaciones que se tomen en la segunda tendrán impacto en las determinaciones que se tomen en la primera, máxime cuando las resoluciones de la CoIDH son vinculantes para la SCJN al haber aceptado el Estado mexicano la jurisdicción supranacional de este tribunal.

Todo ello se originó por las modificaciones al artículo $1^{\circ}$ constitucional, devenidas del paquete de modificaciones aprobadas en la Cámara de Diputados el 15 de diciembre de 2010, y que a la postre la Cámara de Sanadores señalaría como "el corazón de la reforma", es justamente en este artículo en donde se ve el cambio sistemático en la concepción del reconocimiento y protección de los derechos humanos, porque ya no sólo serán aquellos que se encuentren establecidos en la CPEUM, sino también en los tratados internacionales de los que el Estado mexicano es parte, tal es el caso de la Convención Americana sobre Derechos Humanos, entre otros instrumentos internacionales ratificados o aprobados por el Senado de la República en los términos de lo señalado por la fracción I del artículo 72 de la CPEUM.

\section{El sistema federal en México}

Con la primera Constitución Mexicana (1824), en México se estableció una república federal después de la Independencia Nacional, por lo cual se estableció la existencia de los estados o entidades federativas. El nacimiento del federalismo en México, copiado del federalismo estadounidense debido al gran prestigio que en poco tiempo logró, fue tomado como modelo constitucional (model constitution) para el nuevo Estado Mexicano, instauró en nuestra CPEUM “dos órdenes o ámbitos normativos que funcionarían de manera simultánea: el federal y el local" (Ramos Quiroz, 2011, p. 68).

Y este federalismo "a la mexicana", se repitió en las posteriores constituciones de 1857 y 1917, y particularmente ésta última lo establece en los artículos 40 y 41 primer párrafo. El federalismo mexicano, adoptó el modelo de federalismo dual norteamericano (dual federalism) pero al mismo tiempo, quizá de manera indirecta, reconoció la enorme diversidad y pluralidad existente en México: el norte no era el centro, y éste no era el sur; pareciera que se encontraban tres Méxicos unidos en un mismo territorio, y si a eso se agrega la gran cantidad de comunidades y pueblos indígenas, se trataba sin lugar a duda de un México megadiverso.

Así cada entidad federativa, adoptó una Constitución Particular, como es el caso de Guanajuato, que buscó reconocer las particularidades propias de cada región, aunque se debe reconocer que siempre existió y existe la tentación de las autoridades federales de homogeneizar un país que por sus propias características es diverso, ejemplos de ellos hay muchos: la creación de Códigos Nacionales, de Códigos Únicos, de Leyes Generales o Leyes Nacionales, no son más que intentos de homogeneizar jurídicamente un país que es diverso. En otras palabras, "si queremos entender el constitucionalismo mexicano, se debe tener a la vista, en perspectiva el modelo heterogéneo diseñado en las cartas políticas y los patrones 
culturales que caracterizan a cada unidad constitutiva de la Federación" (Madero Estrada, 2012, p. 85).

Bajo el esquema federal, con entidades federativas independientes una de la otra y unidas bajo un "pacto", "se habla de la existencia de dos constituciones, la federal y la local de cada una de las entidades federativas" (Rascado Pérez, 2012, p. 65). Sin embargo, la teoría constitucional se desarrolló tomando en cuenta a "una sola constitución nacional"; de tal manera que bajo las doctrinas de" la teoría constitucional, sustentada en el principio de supremacía constitucional, la soberanía y teoría del poder constituyente, no se justifica la existencia de las constituciones locales" (Rascado Pérez, 2012, p. 65).

Este paradigma constitucional ha cambiado, dado que bajo un paradigma de un "auténtico federalismo", la Constitución Particular de cada una de las entidades federativas en México deben ser consideradas como "el ordenamiento político fundamental de una entidad federativa, por medio de la cual se organiza su gobierno asegurando su sistema de libertades y el respeto a la dignidad humana de la población. Al interior de dicha entidad, la Constitución es la norma jurídica y política fundamental, a partir de la cual se construye todo el sistema normativo y social" (Madero Estrada, 2012, p. 86).

Bajo un empirismo constitucional, la prueba de la existencia de este nuevo paradigma, en términos de Khun y Popper, significa que la "sola existencia de la Constitución local es una característica predominante del sistema federal, por cuanto la entidad federativa se otorga sus atributos políticos fundamentales: libertad y soberanía en su régimen interior". (Madero Estrada, 2012, p. 89). El federalismo en México se prueba con la existencia de Constituciones Locales, eso no está en duda; lo que se cuestiona es el alcance jurídico de las disposiciones consagradas en la misma, tanto desde un plano adjetivo como sustantivo.

En este contexto, la CPEUM le concede a cada entidad federativa la facultad de regular su propio régimen interior, sin contradecir o ir más allá de lo que la misma señale, dado que existe un "pacto federal", que tomado como punto máximo, permite a cada una de las Constituciones Locales ser una "entidad como parte del todo federativo y, luego, a dicha entidad, autónomamente, corresponde promulgar su propia Constitución, sin intervención de ninguna autoridad federal" (Madero Estrada, 2012, p. 89).

Las Constituciones locales son diferentes, pues posibilitan que su articulado desarrolle de una manera más detallada y explicita lo que la CPEUM establece, con una orientación estricta de construcción constitucional ${ }^{1}$ (Swindler, 1971, p. 593); el que las constituciones locales se limiten a reflejar en su articulado exactamente lo mismo que la CPEUM sin incorporar nada adicional, refleja una renuncia que hacen los legisladores locales a esa posibilidad que tienen de construir su propio ordenamiento local constitucional.

En otras palabras, las Constituciones locales, no son una simple versión miniatura de la CPEUM, más bien, ellas difieren de su contraparte federal en el lenguaje, en el carácter básico, en su historia y el lugar que ocupa su constitución local en la misma, y su filosofía

\footnotetext{
${ }^{1}$ La traducción es propia y la cita textual es: "State Constitutions are all too detailed and explicit [and] there is a built-in orientation toward strict construction [i.e., textual analysis]".
} 
política $^{2}$ (Tarr, 2011, p. 3). En otras palabras, el constitucionalismo local impacta en el texto de la constitución particular de cada entidad federativa, que se convierte en un documento en construcción, en una constitución cultural, "la expresión de un cierto grado de desarrollo cultural, un medio de auto representación propia de todo un pueblo" (Häberle, 2000, p. 34).

Para considerar a una Constitución Local como parte del modelo federal en estricto sentido jurídico se deben cumplir con las siguientes condiciones: "a). Dar contenido a todos los elementos esenciales de una Constitución; b). Ser la norma suprema de la unidad constitutiva de la Federación, c). Respetar los parámetros del orden político y jurídico establecido en la Constitución Política de los Estados Unidos Mexicanos; [...] d). Servir como un cauce de libertades para la gobernabilidad democrática del pueblo" (Madero Estrada, 2012, p. 89).

En este sentido la Constitución Particular de una entidad federativa se define como "el documento solemne mediante el cual el pueblo del estado define su concepción de la justicia y de los derechos individuales, que orientan y rigen la vida en sociedad, y que sirven de basamento para crear el gobierno y atribuirle poderes o competencias para llevar a efecto ese ideal de justicia” (Barceló Rojas, 2005, p. 67).

Se puede decir entonces que "el federalismo aduce a un pacto jurídico-político entre las entidades y el Estado (nacional); una especie de compromiso alcanzado a partir de la compaginación de la libertad y la autonomía, en el que las entidades federativas que lo componen deben tener el espacio vital necesario para su desenvolvimiento, el cual consiste principalmente en expedir sus normas de organización” (González Torres, 2008, p. 100).

Bajo este modelo de Estado federal, la Constitución Local es la norma suprema, convirtiéndose en "la máxima expresión jurídico-normativa de este, atento a que de ella derivan las normas secundarias y demás actos que tienen vigencia o imperan en esa entidad federativa" (Castillo del Valle, 2013, p. 101). Y en este contexto, "Las constituciones locales representan el fundamento de validez de toda legislación estatal, de los actos de la autoridad local y de los derechos de los cuales viven en las entidades federativas" (Corzo Corral, 2010, p. 99).

De ahí que la CPEUM, en este modelo de Estado federal se debe limitar, como así lo hace en el artículo 116, a "establecer las características mínimas que debe contener la estructura y funcionamiento de las entidades federativas que componen la Federación Mexicana. Empero, una vez cumplidas las reglas establecidas en el citado numeral, los estados pueden organizarse con la más amplia libertad, dentro de su esfera de competencia" (Corzo Corral, 2010, p. 99).

Ello es así porque dicho numeral constitucional señala en su segundo párrafo que "Los poderes de los Estados se organizarán conforme a la Constitución de cada uno de ellos, con sujeción a las siguientes normas:" señalando los mínimos constitucionales federales, dejándole a las constituciones particulares de los Estados su regulación particular sobre

\footnotetext{
${ }^{2}$ La traducción es propia y la cita textual es "State constitutions are not simply miniature versions of the United States Constitution, rather, their differ from their federal counterpart in their language, basic character, generating history, place in the state's constitutional history, and underlying political philosophy".
} 
materias propias de cada entidad federativa en el marco del artículo 124 de la misma constitución.

Sin embargo, "El federalismo es un proceso y por tanto el pacto inicial debe concebirse como un acuerdo que incluye su posterior adaptación a las nuevas realidades" (Tornos Mas, 2013, p. 114); ser flexible, sin que ello signifique el rompimiento del "pacto federal", pero si una adecuación al modelo de acuerdo con el avance democrático que experimente el Estado mexicano en su desarrollo histórico. El modelo de Estado federal no es único, sino que depende del propio constitucionalismo, lo que en su momento determina su desarrollo posterior; el federalismo no es algo dado sino es el producto de una construcción cultural que se da a lo largo del desarrollo de un pueblo. Y es aquí donde entra la justicia constitucional, en el planteamiento de un modelo federal que permita a las entidades federativas asumir sus propias facultades y responsabilidades, establecer nuevos mecanismos de control constitucional (como es el caso del amparo local en Guanajuato), pero también la posibilidad de incorporar en los textos constitucionales locales, nuevos derechos humanos, adicionales a los existentes en los tratados y en la propia CPEUM y que incorpore mecanismos procesales constitucionales locales como herramientas para hacer el acceso a la justicia, algo más expedito y efectivo, en el marco del desarrollo global del derecho.

\section{Un nuevo sector del derecho procesal constitucional}

El siglo XXI, además de enormes retos que enfrenta la humanidad en materia sanitaria, en donde la aparición de una nueva sepa del coronavirus, científicamente identificado como SARS-CoV-2 o Covid 19, de ahora en adelante coronavirus, ha puesto en riesgo a la comunidad internacional, en todos los ámbitos: internacional, nacional y local; dejando patente que el mundo se encuentra interconectado, y que algo que puede ser eminentemente local en un país de una región del planeta, puede llegar a tener efectos de carácter global y que por lo tanto se deben considerar todas aquellas opciones que desde lo local pueden solucionar un problema que también surgió en el ámbito local.

Esto mismo pasó en el campo del derecho, en donde derivado de múltiples fenómenos jurídicos de alcance global, principalmente lo relacionado a los tratados internacionales en materia de derechos humanos y la existencia de una jurisdicción supranacional, se replantearon modelos al interior de las naciones, que durante mucho tiempo se consideraron inamovibles, tal es el caso del modelo de Estado federal, en donde uno de sus formantes, es la existencia de dos constituciones, una nacional y otra local.

Y es precisamente en esta última, en donde se empiezan a desarrollar mecanismos jurisdiccionales protectores de derechos humanos, no sólo los existentes en el orden internacional y nacional, sino también aquellos que se encuentran en las Constituciones locales, un bloque tripartito de derechos: tratados, constitución nacional y constitución local.

Como lo plantea Arteaga Nava, "En el nivel local, existe un ordenamiento normativo, al que se denomina Constitución, que es de naturaleza suprema; ello implica, por una parte, que hay un complejo normativo, integrado por leyes, decretos, bandos y acuerdos generales, que es de índole secundaria y derivada; y por otra, que existen poderes y autoridades locales, que 
son, por partida doble constituidos, cuya existencia y actuación está prevista y regulada por ese orden normativo y particulares que están sujetos a lo que él disponga" (2002, p. 11).

Es decir, en el ámbito local existen autoridades que en el marco del derecho global tienen sus propias facultades derivadas de un documento supremo como lo es su Constitución local, y una transgresión a alguno de los derechos consagrados en esa Constitución, que en el orden interno estatal, es fundamental y suprema, implicaría la activación del amparo local para aquella persona a la que se le vulnere un derecho humano consagrado en la misma; sin embargo, el desarrollo constitucional local ha tenido muchos obstáculos, entre los que destacan:

a) Falta de conocimiento, análisis y difusión del derecho constitucional estatal.

b) La aparente similitud entre la Constitución Federal y las constituciones de los estados y lo innecesario, por consiguiente, de un estudio específico en lo concerniente a éstos últimos ordenamientos.

c) La falta de voluntad política de los estados para asumir la responsabilidad de fortalecer el autogobierno, sustentándose en las particularidades regionales y en las exigencias y necesidades de los ciudadanos de la entidad.

d) La falta de voluntad real del gobierno federal para reconocer y fortalecer la autonomía de los Estados; y

e) la restringida libertad que la Constitución Federal otorga a las legislaturas locales para estructurar su forma particular de gobierno (Ávila Lamas y Ávila Veyna, 2002, p. 35).

Sin embargo, "en el sistema jurídico mexicano, la naturaleza suprema de las constituciones locales se desprende: a) De lo dispuesto por el artículo 41 de la constitución federal [...] b) De lo que disponen en forma expresa y terminante algunas de las Constituciones de los Estados, como las de los Estados de Veracruz (80) y Colima (129)" (Arteaga Nava, 2002, p. 14).

Las constituciones de los Estados en México, entre ella la de Guanajuato, son de naturaleza suprema "por cuanto a que regulan la organización de ellos (Estados), establecen sus facultades, norman su actuación y les establecen limitaciones, obligaciones e inhibiciones" (Arteaga Nava, 2002, p. 14).

Por lo tanto, las autoridades locales ordinarias deberán atender no sólo lo señalado por la CPEUM, sino también por lo señalado en su respectiva constitución particular, en lo que expresamente se encuentre establecido en la misma, como puede ser el tema de los derechos humanos que estén expresamente consagrados en estas Constituciones locales.

Por ello es que se afirma que existe un nuevo sector del derecho procesal constitucional denominado "Derecho Procesal Constitucional Local" que "comprende el estudio de los distintos instrumentos encaminados a proteger los ordenamientos, constituciones o estatutos de los Estados, provincias o comunidades autónomas [...] al consolidarse un subsistema de mecanismos locales de control y en algunos casos "Salas Constitucionales" (Veracruz, Quintana Roo y Estado de México) e inclusive un "Tribunal Constitucional" (Chiapas)" (Ferrer Mac-Gregor, 2013, p. 58). 
Con esta nueva área de estudio, se considera que las Constituciones de las Entidades federativas de México, además de reconocer nuevos derechos humanos, distintos incluso a los señalados en los tratados internacionales de los que el Estado mexicano sea parte, también puede establecer "distintos mecanismos de protección constitucional, cuya competencia se atribuye al Poder Judicial Estatal (sea el Pleno o a una Sala Constitucional o Sala Superior). Lo anterior descansa en un principio de supremacía constitucional local" (Ferrer MacGregor, 2005, p. 39).

\section{El estudio del derecho procesal constitucional local}

En su origen, el Derecho Procesal Constitucional tuvo tres grandes exponentes: a) Hans Kelsen quien desde 1928 con su artículo denominado como: Le garantie juridictionelle de la Constitution: La justice constitutionnelle (1928) siembra la semilla de una nueva rama científica del derecho, b) luego Niceto Alcalá-Zamora y Castillo considerado como el fundador de este nuevo Derecho Procesal Constitucional y finalmente c) Hector Fix-Zamudio a quien se le considera como el sistematizador, el que le da su contenido a esta rama de la ciencia del derecho.

Una de las realidades bajo las cuales se desarrolla esta investigación, es la parte correspondiente a la ciencia jurídica, es decir como parte del derecho procesal o como una vertiente del derecho constitucional, cualquiera que sea la orientación epistemológica que se le quiera dar, lo relevante es que "surge una disciplina científica del Derecho procesal y del Derecho constitucional, ambas como fruto del Derecho público alemán del siglo XIX" (Ferrer Mac-Gregor, 2013, p. 79).

Héctor Fix-Zamudio define al Derecho procesal constitucional como:

La disciplina que se ocupa del estudio de las garantías de la Constitución, es decir, de los instrumentos normativos de carácter represivo y reparador que tienen por objeto remover los obstáculos existentes para el cumplimiento de las normas fundamentales, cuando han sido violadas, desconocidas o existe incertidumbre acerca de su alcance o de su contenido, o para decirlo con palabras carnelutianas, son las normas instrumentales establecidas para la composición de los litigios constitucionales (Ferrer McGregor, 2013:97).

Particularmente, el Derecho Procesal Constitucional Local "comprende el estudio de los distintos instrumentos encaminados a proteger [...] los ordenamientos, constituciones o estatutos de los Estados, provincias o comunidades autónomas" (Ferrer McGregor, 2005:43), así como la creación de los órganos encargados de implementar tales instrumentos como lo son las Salas Constitucionales Locales, los Plenos de los Poderes Judiciales de los Estados, o incluso la creación de un Tribunal Constitucional Local, todos con la facultad de conocer de los conflictos en defensa de la autonomía local.

Ello bajo un marco teórico de una auténtica supremacía constitucional estatal, fundada en lo señalado por el artículo 40 de la Constitución Federal que a la letra dice: 
Artículo 40. Es voluntad del pueblo mexicano constituirse en una República representativa, democrática, laica, federal, compuesta de Estados libres y soberanos en todo lo concerniente a su régimen interior; pero unidos en una federación establecida según los principios de esta ley fundamental.

Bajo este esquema, y en el marco de una supremacía constitucional local, las Cartas Magnas Locales no solamente establecerían nuevos instrumentos procesales constitucionales capaces de defender la autonomía local (como el amparo local), y las decisiones que tomen las autoridades locales, sino además, tienen la posibilidad de incorporar nuevos derechos, como ya se estableció, adicionales a los que se encuentran en los tratados internacionales en el marco de una globalización jurídica, y en la CPEUM.

Con la modificación al artículo 1 de la CPEUM, se "generó una enorme apertura en relación con el reconocimiento y defensa de los derechos humanos y [...] planteó nuevos retos a las autoridades jurisdiccionales locales para ver la forma de hacerlos exigibles, como, por ejemplo, a través del juicio de amparo local en una forma de control concentrado de constitucionalidad" (Collí Ek, 2019, p. 33).

Con ello, en el marco de la globalización jurídica, se abre la "posibilidad de que las autoridades jurisdiccionales locales pudieran ejercer un control convencional en relación a los tratados internacionales de los que el Estado mexicano es parte" (Collí Ek, 2019, p. 52), reconociéndose que esos derechos humanos de fuente internacional también son exigibles a las autoridades locales, y que para ello, deben contar con instrumentos procesales constitucionales (como el amparo local) que posibiliten el cumplimiento de esa obligación internacional, asumida por el Estado mexicano en su conjunto, pero exigible al interior de cada una de las entidades federativas; y eso marca un nuevo paradigma en el constitucionalismo mexicano.

Esta nuevo paradigma constitucional de ver a los derechos humanos al interior de México, significa que además de los derechos humanos y de los mecanismos procesales constitucionales supranacionales que se encuentren en los tratados internacionales, negociados por el Presidente de la República en los términos señalados por el artículo 89 fracción X de la CPEUM, y aprobados o ratificados por el Senado de la República en los términos señalados por el artículo 72 fracción I de la misma CPEUM, también se deberán atender los derechos humanos y mecanismos procesales constitucionales nacionales (amparo federal) y además, los derechos humanos e instrumentos procesales constitucionales locales (amparo local) que se encuentren estipulados en cada una de las Constituciones Particulares de las entidades federativas que conforman el Estado mexicano.

Hasta la actualidad, en México para garantizar o hacer efectivos estos derechos humanos, con independencia de su fuente, se sigue recurriendo al juicio de amparo federal, mecanismo procesal constitucional (en términos de don Héctor Fix-Zamudio), que sigue siendo el único juicio que puede ser emprendido por las personas, sean físicas o morales, para defender violaciones a sus derechos humanos; esto cambió con la reforma constitucional del 2011, y es aquí donde incide la propuesta desarrollada en esta investigación, adicionar, además del amparo federal, al amparo local en Guanajuato, como forma de ampliar las garantías 
procesales de las que el gobernado puede echar mano cuando un derecho humano le sea afectado.

Consecuentemente, en materia de justicia constitucional local en el aspecto procesal, la CPEUM en su artículo 1, establece la obligación de todas las autoridades, incluyendo las jurisdiccionales locales, de garantizar el respeto a los derechos humanos establecidos tanto en los tratados, la propia CPEUM así como en las Constituciones Particulares de las entidades federativas, por lo tanto, las autoridades jurisdiccionales locales pueden establecer un control constitucional local sobre normas de su propia entidad federativa.

\section{La defensa de la constitución local. Justicia constitucional local}

La Constitución local, como norma jurídica vinculante, se ha desarrollado a partir de la previsión de un conjunto de instrumentos dirigidos a tutelar su supremacía y fundamentalidad al interior de cada una de las entidades federativas. Estos instrumentos procesales constitucionales han adquirido diferentes formas: amparo local, acción de inconstitucionalidad local, cuestión de inconstitucionalidad local, acciones por omisión legislativa, etc., que tienen como propósito limitar al poder y hacer que sus decisiones sigan los cauces definidos por la propia norma constitucional local, y frente a su vulneración o desconocimiento, activar los instrumentos procesales locales que permitan la reintegración del orden constitucional.

Sin embargo, en términos generales dentro del concepto amplio de defensa constitucional local, se pueden mencionar dos que tienen el carácter reparador: a) los que conforman lo que se conoce como protección de la Constitución, y b) los de carácter procesal conforman el apartado de y que se conocen como garantías constitucionales. En el caso mexicano, existen ambos mecanismos procesales de defensa de la Constitución local.

Dentro de los primeros, se encuentran aquellos que posibilitan la racionalidad del poder, el checks and balances, como lo es la división del poder (áreas de competencia: local y federal), la aprobación a reformas constitucionales nacionales por parte de las legislaturas de los estados, y en algunos casos los vínculos que se establecen con organismos constitucionalmente autónomos como lo es la Comisión Nacional de Derechos Humanos. Todo con la intención de propiciar la participación de las entidades federativas mexicanas en los asuntos más importantes del país.

Y dentro de los segundos, se encuentran todos aquellos instrumentos procesales constitucionales locales o garantías procesales que buscan defender la Constitución local al interior de cada una de las entidades federativas de México, como "la omisión inconstitucional del legislador, el control previo de constitucionalidad, y la cuestión de inconstitucionalidad, todo ello en sistemas de control de constitucionalidad, que de manera reciente han evolucionado hacia sistemas de naturaleza mixta, que hacen convivir modalidades de control concentrado con un renovado control difuso de constitucionalidad" (Ferrer Mac-Gregor et al., 2014, pp. 240-242).

Este tipo de control constitucional es lo que se ha denominado justicia constitucional locales, que "se puede analizar desde dos perspectivas, primero como un autocontrol de los poderes 
judiciales locales, al otorgarle prioridad al cumplimiento de su propia constitución, en términos del artículo 133 de la Constitución federal o como medio de resolver las controversias entre el estado y sus municipios" (De la Fuente Alonso, 2010, p. 3 ).

\section{Instrumentos procesales constitucionales locales}

El desarrollo de los instrumentos procesales constitucionales locales que entran dentro de lo que se conoce como garantías constitucionales locales, bajo un concepto amplio de justicia constitucional, ha variado en cada una de las 32 entidades federativas de México. Algunas entidades han tenido un mayor desarrollo que otras; y en el caso de Guanajuato, su desarrollo ha sido incipiente.

Para probar lo anterior, se ejemplifica de la siguiente manera, en una enumeración ejemplificativa más no limitativa. En Veracruz y Tlaxcala se introdujo la figura del amparo local; en Veracruz, Coahuila, Tlaxcala, Chiapas y Quintana Roo existen las acciones de inconstitucionalidad, como mecanismos abstractos para impugnar normas generales de la entidad federativa, en estas misma entidades federativas existen las controversias competenciales o constitucionales locales; en Tlaxcala, Veracruz, Chiapas y Quintana Roo se incorporaron en sus respectivas Constituciones locales el mecanismo de acción por omisión legislativa; en el caso de las entidades federativas mexicanas de Coahuila y Chiapas se creó la garantía procesal de la cuestión de inconstitucionalidad; f) y particularmente, en el estado de Coahuila se incorporó en su Carta Magna local, el denominado Control difuso de constitucionalidad local (Ferrer Mac-Gregor, 2005:53).

Estos instrumentos procesales constitucionales han sido atribución de órganos jurisdiccionales locales de carácter concentrado principalmente, como los son: a) para los Estados de Coahuila, Guanajuato y Tlaxcala las atribuciones las tiene el Pleno de los Tribunales Superiores de Justicia; b) para las entidades federativas de Veracruz, México, Nayarit y Quintana Roo, la competencia la asumen las denominadas Salas Constitucionales y como único estado en el país, Chiapas creó su propio Tribunal Constitucional Local.

Estos nuevos mecanismos procesales constitucionales y los órganos que tienen competencia para conocerlos buscan fortalecer el federalismo mexicano desde el punto de vista jurídico, dotando de competencias y de órganos a las entidades federativas, para que puedan de una manera más eficaz y eficiente, hacer de la justicia local un baluarte de reconocimiento nacional e internacional en el marco de una globalización jurídica. Ello sin lugar a dudas representa el gran reto del siglo XXI para los estudiosos del derecho, toda vez que derechos humanos siempre han existido si tomamos en cuenta la Carta Magna de Juan Sin Tierra de 1215; lo que ha faltado, son mecanismos procesales constitucionales, en este caso locales, que hagan realidad esos derechos, pues sin instrumentos, los derechos se convierten en "buenas intenciones", o cuando mucho, en una "declaración de principios", sin mayor obligatoriedad en su cumplimiento por las autoridades locales.

\section{Amparo local en Guanajuato como mecanismo de justicia constitucional}

En el año 2000 se realizó la reforma integral de la Constitución Política de Estado de Veracruz Llave y se incorporó el juicio para la protección de derechos humanos (amparito o 
amparo local), mecanismo procesal constitucional que fue impugnado a través del mecanismo de controversia constitucional federal (controversias constitucionales 10/2000, $15 / 2000,16 / 2000,17 / 2000$ y 18/2000), pues se consideró que con dicho juicio se invadía la esfera de competencia de los tribunales federales, obviamente, tomando en cuenta que ya existía el juicio de amparo a nivel federal.

Al resolverse los mecanismos procesales constitucionales incoados, el Pleno de la Suprema Corte de Justicia mexicana consideró que dicha reforma era constitucional, pues consideró que conforme a las modificaciones constitucionales a la Carta Magna Local, que incluyeron la creación de una Sala Constitucional que conociera y resolviera, entre otras cosas, el amparo local, no se invadía la esfera de competencia federal, dado que dicho órgano de control constitucional local, tutelaba los derechos fundamentales consagrados en la Constitución local, sin que la Sala tuviere atribuciones para pronunciarse sobre violaciones a los derechos humanos previstos en la Constitución federal.

Esto fue sumamente importante en el contexto del federalismo mexicano, porque se reconoce la existencia de derechos en las Constituciones Locales de cada una de las entidades federativas de México, consecuentemente, existe un bloque tripartito de derechos, aquellos que se encuentran en los tratados, aquellos que están en la Constitución Nacional y aquellos que se encuentran consagrados en cada una de las Constituciones Locales, por lo que no existe un catálogo único de derechos, como tampoco existen solo mecanismos procesales constitucionales federales, sino que los derechos y los instrumentos procesales se consideran parte del régimen democrático de México, o como lo señalara Cesar Astudillo "sin que ello implique que las entidades federativas no puedan maximizar el catálogo de derechos ahí contemplados, con la única limitante de no reducir el contenido de los derechos consagrados a nivel federal" (Astudillo Reyes, 2004).

Con el paso del tiempo, y dado lo señalado anteriormente de la existencia de ampliar derechos, pero también ampliar mecanismos procesales constitucionales locales, otras entidades federativas mexicanas, además de Veracruz, modificaron su Carta Magna Local e y se modernizaron en materia de justicia constitucional local, tal es el caso de los estados de Tlaxcala, Querétaro y Nayarit, Querétaro, Nayarit entre otros, no así en el Estado de Guanajuato, en el que no obstante de que se incluyeron dos mecanismos de justicia constitucional local como lo son la controversia legal (no constitucional) y la acción de inconstitucionalidad, se fue omiso para incluir al amparo local.

Cabe mencionar que, en Guanajuato, el órgano constitucional local designado para conocer de los mecanismos procesales constitucionales antes mencionados, lo es el Pleno del Supremo Tribunal de Justicia del Poder Judicial del Estado, debido a que seguramente tampoco se consideró oportuno crear una Sala Constitucional como en otros lugares ya se había hecho.

Uno de los grandes temas, que impidieron la incorporación del juicio de amparo local en Guanajuato, fue precisamente la existencia del juicio de amparo federal, y según diversas entrevistas realizadas con destacados juristas y ex integrantes del Poder Judicial, se consideró que si ya existía dicho mecanismo en el ámbito federal, era ocioso crearlo en el ámbito local, además de que las resoluciones que se adoptaran en el ámbito local, eran recurribles a nivel 
federal, precisamente acudiendo a incoar el juicio de amparo en dicho ámbito, por lo que para el gobernado resultaba ocioso acudir en primer lugar al amparo local y luego al amparo federal, pudiendo acudir, por economía procesal, directamente al amparo federal.

$\mathrm{Y}$ es precisamente en este ámbito en donde también existe un gran reto para la justicia constitucional mexicana, toda vez que debe de existir un principio de lealtad institucional entre poderes judiciales (quizá tomando como referencia el modelo alemán), es decir, bajo un principio de derecho de opción, como existe a nivel de nacionalidad en el derecho internacional privado, si el justiciable decide acudir a la competencia de los tribunales locales para iniciar un juicio de amparo local, las autoridades judiciales federales deben respetar esa decisión, bajo el principio de autonomía de la voluntad, de tal suerte que se debe negar a conocer de un juicio de amparo cuando este ya ha sido incoado a nivel local.

Y viceversa, si el justiciable decidió optar por el juicio de amparo federal, el poder judicial local, debe declararse incompetente. De tal manera que el justiciable, al momento de ejercer su derecho de opción en el ámbito de la justicia constitucional, deberá determinar ante cual instancia le satisface mejor su derecho de justicia, y actuar en consecuencia, con la clara consecuencia de que, una vez que opta por un mecanismo, se deberá atener a la resolución que se adopte, ya sea a nivel local o federal, sin posibilidad de recurrir ante otra instancia, la determinación que se haya adoptado en el mecanismo de justicia constitucional elegido de manera libre.

Esto es muy difícil que suceda sino existe una modificación a la Constitución Política de los Estados Unidos Mexicanos, es decir, en un modelo federal, (mal llamado pacto federal), como lo es el mexicano, es clara la tendencia al centralismo desde el punto de vista estrictamente jurídico, por ejemplo, existe el artículo 124 de nuestra Carta Magna Nacional que establece el principio residual, es decir, todo aquello que no esté expresamente asignado competencialmente a las autoridades federales le corresponde a las locales, lo que significa en la realidad, que basta modificar el artículo 73 y asignarle una nueva facultad a las autoridades federales y dejar sin ella a las autoridades locales, se podría alegar que para ello los congresos locales deben de dar su aprobación cuando se modifica la Constitución Nacional Mexicana, pero en la realidad este mecanismo de "intervención local en la modificación constitucional” es inoperante para los efectos planteados.

Pero, además, existe una obstaculización competencial para las entidades federativas de México a nivel constitucional y en dos grados. Es decir, existe el artículo 117 de la CPEUM en donde se prohíben competencias para las entidades federativas, esto es un grado de prohibición absoluta; pero además existe el artículo 118 de la CPEUM, que establece aquellos asuntos con un grado de prohibición relativa, es decir, si pueden las entidades federativas de México, pero con la aprobación del Congreso de la unión.

Si esto no es centralismo constitucional competencial, entonces, ¿qué será?; ahora bien, si existen prohibiciones absolutas y relativas para las entidades federativas, ¿por qué no existen competencias exclusivas para las entidades federativas?, es decir, un catálogo de competencias, que generaría derechos para el gobernado, en donde sólo la entidad federativa con exclusión de la autoridad federal, pueda conocer de determinados asuntos, y por lo tanto, 
solo mecanismos locales constitucionales (como el amparo local), pueden ser incoados por el justiciable, y las determinaciones adoptadas en el ámbito local serían definitivas.

Para ello se requiere, adicionar la CPEUM con un artículo 117 bis, en donde se establezcan todas aquellas competencias exclusivas de las entidades federativas, lo que propiciaría derechos locales, y, por consiguiente, mecanismos procesales constitucionales y órganos judiciales locales que hicieren efectivos dichos derechos bajo el principio de una tutela judicial efectiva.

\section{El amparo local en un marco de justicia global}

En un mundo interconectado por los medios electrónicos de comunicación, que en tiempos de emergencia sanitaria propiciados por el coronavirus, han generado que su uso se intensifique al grado de obligar a la realización de una actividad académica a distancia con el apoyo de plataformas educativas, es imposible considerar que la justicia constitucional sólo se desarrolla en un marco nacional o local sin tener implicaciones en un ámbito supranacional a nivel jurisdiccional derivado de la existencia de tratados internacionales de los que el Estado mexicano es parte.

Efectivamente, conforme lo estipulado por la Carta Magna mexicana en términos de lo señalado por los artículos 76 fracción I, 89 fracción X y 133 todos relacionados con los párrafos primero y tercero del artículo 1; una vez que el Presidente de la República negocia un tratado internacional y éste es aprobado por el Senado, forman parte del sistema jurídico mexicano; y por lo tanto, todas las autoridades en el marco de sus respectivas competencias están obligados a observarlo; máxime si se trata de tratados en materia de derechos humanos y de tutela judicial en lo específico.

De no observarse un tratado internacional en el ámbito competencial de las autoridades nacionales, su incumplimiento genera responsabilidad internacional para el Estado, que generalmente es determinada por jurisdicciones supranacionales como lo son la Corte Internacional de Justicia, la Corte Penal Internacional y la Corte Interamericana de Derechos Humanos, sólo por mencionar algunas jurisdicciones que han sido aceptadas por México.

En la actualidad existe una interconectividad entre las distintas jurisdicciones, a lo que ha venido denominándose un diálogo; si en una jurisdicción local no se garantizan los derechos humanos consagrados en los tratados internacionales, el caso puede escalar hasta la jurisdicción supranacional para convertirse en litigio estratégico en donde el Estado pierde su carácter de autoridad para colocarse en una situación de parte procesal en el litigio.

Por ende, el acceso a la justicia para el gobernado debe empezar en el ámbito local, con la existencia de mecanismos procesales constitucionales locales como lo es el amparo local, que sean destinados a proteger los derechos humanos de todas las personas en su mismo lugar de residencia, con un acceso a la justicia rápido y efectivo que se lograría de establecer mecanismos procesales constitucionales locales (justicia constitucional local).

Es en el ámbito local en donde deben hacerse efectivos los derechos humanos consagrados por los tratados, y no solamente en un ámbito nacional o federal, toda vez que de su 
observancia y garantía se alcanzarán aquellos ideales de justicia universal pensados como objetivos por la comunidad internacional al momento en el que decidieron negociar un tratado; y que generalmente se encuentra en el proemio o parte declarativa del mismo.

Hacer un análisis de los artículos y de los tratados internacionales que tienen relación directa con la creación del mecanismo procesal constitucional denominado como amparo local en la Constitución Particular del Estado Libre y Soberano de Guanajuato, México, excedería el planteamiento del objeto de investigación determinado en la parte introductoria de esta investigación, en este momento baste decir que su relación es innegable y que contribuye de manera objetiva en la ampliación de los mecanismos de acceso a la justicia, tan necesarios en un mundo globalizado, no sólo por el derecho, sino también por las pandemias.

\section{Conclusiones}

En un mundo globalizado por el derecho, la evolución de los derechos humanos y su justiciabilidad en México resultan innegables. El reto que existe al interior de las entidades federativas, en un marco global, es que éstas puedan crear y definir sus propios mecanismos procesales de justicia constitucional local, como lo es el amparo local, mismo que ya existe en algunas entidades federativas, como un mecanismo de control constitucional local, desde la perspectiva de control concentrado; y que en caso de Guanajuato, su desahogo procesal se propone lo realice el Pleno del Supremo Tribunal de Justicia del Poder Judicial del Estado de Guanajuato, con el respaldo de las autoridades jurisdiccionales federales, al otorgarles definitividad a las resoluciones adoptadas bajo la estructura procesal constitucional de este mecanismo de control constitucional local.

La hipótesis o respuesta a la pregunta de investigación es que la inclusión del juicio de amparo local como un nuevo mecanismo de justicia constitucional local, impactará positivamente en el acceso a la justicia, sobre todo de aquella población que tiene menos recursos o se encuentra en uno de los grupos identificados como vulnerables.

Por ello, se propone la adición de la fracción XV de la Constitución Política del Estado Libre y Soberano de Guanajuato para incluir al amparo local como un nuevo mecanismo de justicia constitucional local, y la correspondiente adición a la Ley Reglamentaria de la Fracción XV del artículo 88 de la Constitución Política del Estado de Guanajuato, en donde actualmente sólo se encuentran reguladas la acción de inconstitucionalidad y la controversia legal; para incluir la regulación del amparo a nivel local.

Con ello se fortalece el federalismo, al propiciar que las propias entidades federativas de la República mexicana, bajo el marco conceptual de las teorías sobre fundamentalidad y supremacía constitucional, tendrían a la Constitución de Guanajuato como el documento jurídico más importante que puede tener una Entidad Federativa, que es fundamental, es soberana y suprema, sólo que en el ámbito local, en los términos señalados por el artículo 40 de la Constitución Política de los Estados Unidos Mexicanos. 


\section{Referencias}

Arteaga Nava, Elisur (2002) "La Constitución Local y su defensa. Elementos para una teoría del control de la Constitucionalidad", pp. 11-34. En Ferrer Mac-Gregor, Eduardo y VEGA HERNANDEZ, Rodolfo (Coord.). Justicia Constitucional Local, México: Editorial FUNDAp

Avila Lamas, Salvador y AVILA VEYNA, Norma Angélica (2002) "Hacia el Derecho Constitucional Local” pp. 35-48. En Ferrer Mac-Gregor, Eduardo y vega Hernandez, Rodolfo (Coord.). Justicia Constitucional Local, México: Editorial FUNDAp

Angulo Jacobo, Luis Fernando (2013). "El Control Difuso de Convencionalidad en México", Revista del Instituto de la Judicatura Federal, Num. 35, pp. 71-90.

Casarin León, Manlio Fabio. "El Futuro del Control Constitucional Local: Comentarios a la Contradicción de Tesis 350/2009”, Cuestiones Constitucionales, núm. 24, 2011, pp. 309-319.

Castillo Del Valle, A. (2013). Introducción Básica al Derecho procesal Constitucional Mexicano. México: Ediciones Jurídicas Alma.

Collí Ek, Víctor Manuel (2019). Modelo jurisdiccional de derechos humanos en México. Implementación, evolución y perspectivas, s.e., Mèxico.

Constitución Política de los Estados Unidos Mexicanos, extraída desde www.ordenjuridico.gob.mx; el 12/III/2019.

Constitución Política del Estado de Guanajuato, extraída desde www.congresogto.gob.mx ; el 12/III/2019.

Ferrer Mac-Gregor, E. (2004). Ensayos sobre derecho procesal constitucional, México, Editorial Porrúa, Comisión Nacional de los Derechos Humanos.

Ferrer Mac-Gregor, E. (2005). "Hacia un Derecho Procesal Constitucional Local en México”, pp. 39-54. En GUDIÑO PELAYO, J.J., VEGA HERNANDEZ, J.R.A., Hernandez Perez, C.E. (Coord.) (2005). Controles Constitucionales. Querétaro: FUNDAp.

Ferrer Mac-Gregor, Eduardo (2013). Panorámica del Derecho Procesal Constitucional y Convencional. Madrid: Marcial Pons.

Häberle, Peter (2000). Teoría de la Constitución como Ciencia de la Cultura. Madrid: Tecnos.

Kelsen, Hans (2011). Teoría Pura del Derecho, México: Editorial Porrúa.

Kelsen, Hans (1928). "La garantía Jurisdiccional de la Constitución (la justicia constitucional)", Revue de Droit Public et de la Science Politique en France et a l'Etranger, pp. 197-257..

Ley Reglamentaria de la Fracción XV del articulo 88 de la Constitución Política del Estado de Guanajuato extraída desde www.congresogto.gob.mx ; el 12/IV/2019.

Madero Estrada, J.M. (2012). "Temas a debate del Constitucionalismo Local, Hoy", Quid Juria, Vol. 6, pp. 79-104.

Ramos Quiroz, F. (2011). "La Defensa de la Constitución y su Extensión al Ámbito Local”, De Jure, No. 6, Tercera Época, pp. 50-78.

Rendón Huerta Barrera, Teresita de Jesús y OLGUÍN TORRES, Antonio (2016). "El federalismo en materia de justicia constitucional local en México: El caso de Guanajuato", artículo publicado en la Revista DE JURE, Número 3, Cuarta Época, Año 16. ISSN: 1870-2457. 
Ruiperez Alamillo, J. (1994). La Protección Constitucional de la Autonomía política, Editorial Tecnos, Madrid.

Swindler, William (1971). "State Constitutions for the Twentieth Century", Nebraska Law Review, Volume 50, Issue 4, pp. 577-599.

Tarr, G. Alan (2011). "State Constitutional Design and State Constitutional Interpretation", Montana Law Review, Volume 72, Issue I Winter, pp. 1-20.

Tornos Mas, Joaquín (2013). “Atribuciones y Autonomías en Estados Federales y Estados Unitarios”. En Descentralización, transparencia y seguridad jurídica en América Latina y Europa. Madrid: Instituto Nacional de Administración Pública. 